The remaining essays touch on many other problems, some of relatively minor importance and therefore not well described elsewhere, and others more serious yet sometimes best left alone. Comments are generally sensible and stimulating. The whole makes a remarkable personal contribution to orthopaedics that will be read by many with pleasure and profit. This is no textbook and in no way comprehensive but in his chosen subjects the author has well achieved his original aim.

\section{Contraction and Relaxation in the Myocardium}

By Winifred G. NAYler. Pp. 398, hard cover, illustrated. London: Academic Press, 1975. £8.00.

The editor's personal contributions to the understanding of this topic are well recognized by her colleagues, and deserve to be known by a wider audience. The present book contains eight contributions, each being a paper delivered at a course held by the Cardiothoracic Institute in 1974. Even 2 years later, it still provides an up-to-date review of the various topics. The introductory chapter, by the editor, on the cardiac cell, gives an essential basic description, and goes well with the succeeding chapter on the contractile and regulatory proteins, by S. V. Perry. Other chapters are less even. And at least two of the chapters contain material easily and indeed frequently available elsewhere: Vaughan Williams' chapter on the mode of action on antiarrhythmic agents, and Barrett's on $\beta$-adrenoceptor blockade. The book is much shorter than might be thought from the large number of pages, the style is throughout easy to read where the difficulties of the subject matter permits, and it is a useful addition to research libraries concerned in this field. The individual bibliographical sections have been well chosen, and represent useful reading lists for those who wish to explore the topics more fully.

\section{The Doctor-Patient Relationship. Second Edition}

By Kevin Brown and Paul Freeling. Pp. 101, soft cover. Edinburgh: Churchill Livingstone. $1976 £ 2.25$.

Very few books from general practice reach a second edition. The select band is now joined by Browne and Freeling's work that first appeared 10 years ago.

The new edition is a handier size and easier to read. References have been brought up-to-date, various small revisions have been made, a couple of chapters switched round and two new ones added. The price has more than quadrupled. The changes are not so great that anyone who has a first edition need buy this one.

One of the new chapters is an Introduction, which reviews briefly the changes in general practice in the last 10 years. The authors point out a new and insidious threat to good practice: though we no longer deny the existence and importance of the psychosocial aspects of our patients' lives, we can easily be tempted to believe that our only responsibility is to pass them on to other members of our 'health care team' when the going gets rough, i.e. when psychotropic drugs don't seem to be helping. The authors insist that the general practitioner needs to think very carefully about the ramifications and side effects of all his actions.

The other new chapter, near the end, is called 'Treating the Cause'. It makes no really new points but brings together concepts implicit in other parts of the book. One sentence neatly encapsulates the philosophy of the whole work: 'Any consultation with a conscious patient can never be merely diagnostic'. For the doctor who believes otherwise, the rest can have no meaning.

The new edition gives us an opportunity to look again at the value of the book. The steady stream of references to it, and its automatic inclusion in reading lists for postgraduate examinations in more than one country offer one kind of judgment. Very little of importance has emerged in the last decade that is not covered even in the original edition.

The book's main message was and is that general practitioners should let themselves think about their relationships with their patients and the effects that these relationships are producing. The emphasis is equally upon the letting and the thinking. The authors show how a GP may give himself permission to start, indicate what he should be thinking about, and take the measure of the intellectual rigours involved. They make very clear how these activities affect the quality of the care we give to our patients.

The weakest chapter is probably 'A Matter of Confidence', in which the authors start to explore the difficulties a doctor may get into as a result of his skill in obtaining intimate information from his patients. More of the authors' thoughts would have been welcome before the inevitable injunction that each doctor must sort this problem out for himself.

The book is undoubtedly for a postgraduate audience. It is unlikely that anyone but a general practitioner of some experience could appreciate everything that is said-most of the points are made with vignettes and case-histories from the writers' practices. Vocational trainees should be encouraged to start reading it, and some undergraduates may find it worthwhile.

The readers who will gain most are those who already wish to deal more adequately with the mysterious psychosocial areas of their consultations, but have been held back because they have had no model on which to base a new kind of behaviour. The book offers such a model clearly -although it stops short of offering guidance on what to do when changes in the doctor produce new behaviour in his patients.

The book is now a minor classic. Only those general practitioners with a first edition can safely be advised not to buy the second.

\section{Essentials of Neurology (4th Edition)}

By John N. Walton. Pp. xvii +477 , illustrated, soft cover. Pitman Medical: Tunbridge Wells, Kent, 1975. £6.50.

The aspirant for the MRCP looking at a paperback of 447 pages plus index costing $£ 6.50$ and entitled 'Essentials of Neurology' might well ponder ruefully on the amount he might have to read to include non-essentials. However, with the possible exception of a short chapter on disorders of the mind (which is traditional in neurological text books, but could either have been omitted or transformed into a fuller section on dementia) the book really does deal with essentials. This reflects the change in neurology in recent years from a somewhat esoteric subject into a speciality which pervades all aspects of medicine and in which there are increasing therapeutic possibilities. This perhaps explains the size of the book but not its merit, for it is beautifully written. It is comprehensive and will meet all the requirements of the postgraduate students, yet it is written in a style that is both compressed and readable and where there is a nice balance of priorities. Rare disorders are described neatly and concisely, whilst common conditions receive the detailed consideration they deserve. One could quote numerous examples-picking at random, the pithy but detailed description of the carpal tunnel syndrome which occupies one page is a model of its kind. There is a notable economy of words in an eight line summary of hypertensive encephalopathy and a quite superb chapter on 'Vascular disorders of the nervous system' in only sixteen pages. There is so much in this book that is admirable in style, lucidity and emphasis that it is pertinent to quote Alexander Pope 'What oft was said but ne'er so well before'.

There must of course be a few criticisms from a reviewer who has with pleasure read the book in its entirety. The statement on page 391 that in hypopituitarism ... widespread 